\title{
An Alternative Method Of Accounting For Stock Options
}

Thomas Smith, Florida Atlantic University, USA

Adrian Valencia, Florida Gulf Coast University, USA

Ara Volkan, Florida Gulf Coast University, USA

\begin{abstract}
Currently, the grant date fair value of employee stock options is expensed over the vesting period. Our study introduces a new valuation approach for stock options and examines the impact of this change on earning per share (EPS) for a sample of firms over the period 2002-2011. The new valuation approach provides data useful to the Financial Accounting Standards Board (FASB) as it determines whether to revise the current option accounting rules. Under the proposed approach, options are valued at their intrinsic value on the grant date (i.e., the opportunity cost or the economic promise associated with the difference between the exercise price of the option and the market price of the stock at each measurement date) and further revalued each reporting date until the options are exercised.
\end{abstract}

Keywords: Stock Options; Option Valuation Models; Tax Impact of Options; True Cost of Options

\section{BACKGROUND}

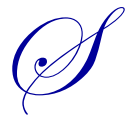

tock options are considered compensation in nature. Thus, the need to measure their impact (value, periodic cost, and expense deduction) on net income is an extremely important issue that the FASB and International Accounting Standards Board (IASB) have addressed (Frederickson, Hodge, \& Pratt 2006). While the accounting standard setting bodies do not primarily concern themselves with tax policy issues, options also have economic impact on a firm's current and potential tax payments and credit rating (Lee 2008).

Applying Financial Accounting Standards (FAS) 123 and FAS 148 (currently ASC Topic 718) and International Financial Reporting Standard (IFRS) 2 can result in different treatments for compensation packages that have similar economic consequences (tax, financial, and cash flow) to both the firm and the employee. The different treatments diminish the representational faithfulness of the reported amounts. In addition, the models of option valuation prescribed by current standards do not readily capture the wealth effects on shareholder value. The option amounts are computed at the grant date and then amortized over the vesting period (static measurement and amortization of the initial amount over a short period). Future changes in option values over the life of the option (a period substantially longer than the vesting period) are ignored. Finally, there are theoretical flaws in stock option recognition and measurement approaches required by both the FASB and the IASB (Amile, 2011).

There is a need for a method that reports more reliable and useful information than the current rules provide. The tax treatment of options (firms are allowed to deduct the difference between the option price and the stock's market price at the date the employee exercises the option) and the accounting treatment of options under current standards are vastly different. The discrepancy was highlighted when the Senate Permanent Subcommittee on Investigations staff asked the IRS to perform analyses to identify the sources of the book-tax differences. The staff also asked nine firms to prepare a schedule comparing the option expenses that they would have reported had they used FAS 123(R) rules to the tax deductions they took. The reports showed that the book and tax differences resulted in tax amounts exceeding 20 billion dollars.

Since valuing and expensing options have been accepted by stakeholders, it is time to take the final step and start to continuously value options until they are exercised and capture the true cost of these transactions in 
company financial statements (McEnroe, Martens, \& Du 2013). Delaying this step in the evolution of option accounting may provide an opportunity for politicians to dominate the FASB through the SEC, using the gap between the reported expenses and the tax deductions taken as an excuse. This study will determine the financial consequences of the proposed accounting method by comparing the EPS resulting from the use of the proposed model to the amounts currently reported.

\section{PURPOSE}

This article aims to present an employee stock option (ESO) accounting model that when compared to the current standards of valuing and expensing options:

- better measures the economic value of the promise made to employees,

- $\quad$ is easy to understand,

- has a low cost of implementation,

- $\quad$ eliminates the need for highly controversial rules that presently impact the cash flow statement,

- $\quad$ offers a superior estimate of the true cash flow effects and economic injury associated with the opportunity cost to shareholders of an option exercise, and

- helps to reduce threats to the legitimacy of the FASB that is unfolding in Congress as the Senate investigates the multi-billion dollar gap between what companies report as expense and what they deduct on the tax returns.

\section{IMPORTANCE AND USEFULNESS OF THE RESEARCH OUTCOMES: THE ISSUE IN A NUTSHELL}

An article by Don Delves (December 2002), reporting on the discussions and conclusions of a panel of experts attending a conference addressing stock options, provided the impetus for this study. Some of the most influential financial professionals in the world were in the panel, including Robert Hertz, representing the FASB, Jim Leisenring, representing the IASB, and Myron Scholes, co-originator of the Black-Scholes option pricing model. The number one question that the company directors should ask was: "What is the true total cost of our stock option package?" The following quotes, taken from the article (p. 40), described the challenge:

"As mentioned earlier, the stock option expense is just the top of the iceberg. This is particularly true for corporate boards that are responsible not only for the long-term success of the company but also for representing and safeguarding the interests of the shareholders. This is important because the expense being proposed by the accounting profession doesn't fully capture the ultimate economic cost of stock options to shareholders. The true economic cost of an option is the spread between the exercise price and market price on the date the option is exercised." .... "For example, if an option is granted with an exercise price of $\$ 10$ when the market price is also $\$ 10$, the likely "new accounting" expense will be somewhere between $\$ 3$ and $\$ 5$. But if the option is exercised five years later when the market price of the stock is $\$ 100$, then the true total cost of the option is $\$ 90 . " . .$. . Someone has to be responsible for this $\$ 90$ cost and for making sure that the company and the shareholders are getting a return on this investment. If the company is only taking a \$5 expense, then the board must make sure that the rest of the cost is tracked and accounted for and that the executives who received this benefit are returning at least that much to the shareholders in improved performance."

Both the FASB and the IASB must abandon the static option valuation and expensing procedures they support and adopt a dynamic model of periodic revaluation of options by marking the value of options to the economic promise at the financial statement dates. In addition, the market based measurement and recognition of option costs must continue after the service period ends (vesting period) and until the options are either exercised or expire. The final standards on option accounting must ensure that both the total amount of wealth that has been transferred from stockholders to executives and the amount that could be transferred in the future are reported. 


\section{FLAWS IN CURRENT STANDARDS}

\section{Private Firm Reports are Representationally Faithful but Public Firm Reports are Not}

While publicly held firms must expense the grant date fair value of the option over the vesting period, privately held firms may elect to measure the option at intrinsic value at the grant date and then re-measure the intrinsic value at each financial statement date until the options are exercised. This approach creates contributed capital amounts that cumulate, with changes in the cumulative amounts recorded as expense at each measurement date (decreases in stock prices will result in negative expenses). Under this approach of continuous valuation of options, deferred tax assets will be equal to the tax impact of the deduction allowed under the tax code. This is ironic because the true cost of options is accounted for by privately held firms, while publicly traded companies use measurements that do not reflect true costs.

\section{Option Valuation Models are Flawed}

From a financial investment perspective, the true economic cost to a firm of utilizing options as a method of compensation is the opportunity cost associated with the difference between the exercise price of the option and the market price of the stock upon exercise (i.e. the economic promise). This intrinsic value represents foregone capital that could have been raised by the firm if the stock had been issued at current market prices. Therefore, the choice of which option valuation model should be used to recognize the option expense should be driven by the determination of which model most accurately reflects this loss of shareholder wealth.

Firms measure the effects of options on financial results using matrix, Black-Scholes (BS), or BlackScholes-Merton (BSM, for stocks that pay dividends) models for option valuation. The BS model is a closed form equation and matrix models are open form equations with probability trees. All models, when supplied with several estimated variables, computes a fair option value that includes both intrinsic and time value components. However, a number of issues make these models poor choices for option valuation to reflect the ESO expense recognition. First, the models were originally developed to value exchange-traded options that have limited lives. Exchange traded options also have a liquid secondary market that facilitates low cost transactions, resulting in regular price discovery. In contrast, stock options are not transferable. In addition, BS was developed to value a European option that cannot be exercised until maturity. Once the vesting period is complete, the ESO can be exercised at the discretion of the employee, in effect an American option. Finally, a key input in these models is volatility. Most volatility estimates are derived from historical returns, leaving no opportunity for the incorporation of changing market conditions and the resulting effects on shareholder wealth (O'Shaughnessy \& Rashty, 2007). Cash Flow Benefits of Excess Tax Deductions Cannot Be Reported in Operating Cash Flows - Reduction in
Tax Outflows Makes the Reported Amount Unreliable for Financial Analysis

Typically, the deferred tax assets recorded when option expenses are accrued cannot counterbalance the tax refund received when the options are exercised, resulting in a credit deficiency in the journal entry. FASB requires that the deficiency be credited to contributed capital and a financing cash inflow be reported in the cash flow statement for the reduction in taxes in excess of deferred tax assets. This highly controversial approach is consistent if one subscribes to the view that issuing options and their tax advantages are primarily a part of the capital raising process. Thus, the excess refunds cannot result in reductions in tax expense and cannot be part of the operating cash flows. However, it is clear that options are equivalent to salary expenses. Company boards grant options to compensate executives and the cash flow to the firm when stocks are issued is a peripheral consideration at best. Thus, accounting for the cash flows resulting from options as if they were financing flows is not appropriate (Siegel, 2006). Indeed, recent research results show that firms increased the use of restricted stock and decreased the use of options in compensation packages after the latest accounting standards were issued, but the total cost of compensation stayed the same (Carter, Lynch, \& Tuna, 2007).

\section{Another Reason to Revise Accounting for Options - The Gathering Storm}

According to the Senate Permanent Subcommittee on Investigations, the current state of option accounting does not make sense. Tax laws allow companies to take deductions that are 400-1200 times the expenses they report. 
Options are the only form of compensation and expense whereby companies are allowed to deduct more on their tax returns in the aggregate than they are allowed to expense in their books. If the expense amounts reported under FAS 123(R) over time and in the aggregate faithfully represent the fair values of the options, the tax rules must change to allow the tax deduction to occur when the options are granted and match the accounting expense amounts. Stated in another way, let two wrongs make a right. To ensure that this proposal to change the tax laws does not occur, the accounting rules must change and reflect the economic promise that they do not currently reflect.

\section{METHODOLOGY-COMPUTING THE IMPACT OF THE PROPOSED MODEL ON EPS}

This study examines earnings per share (EPS) under the currently reported system and under the proposed economic promise approach. The variable EPS_old is the currently reported earnings per share. EPS_new is the earnings per share under the economic promise approach introduced in this study. To measure EPS_new, we first calculate the difference between the stock price and the option exercise price at the end of the year. This difference is then multiplied by the number of options outstanding in order to compute a new stock option expense. The new stock option expense is computed on an after tax basis. For this purpose, we assume an average $30 \%$ tax rate for all companies in our sample. The new expense is then expressed on a per share basis (based on the number of shares used to compute basic EPS). This new stock option expense per share is subtracted from EPS_old while the reported stock option expense per share is added back to EPS_old. Overall, this process results in EPS_new which is subsequently compared to EPS_old. Note that we do not consider the effects on a multi-period basis as we are solely interested in seeing what effects the proposed economic promise approach has on a single-period, as such each fiscal year should be interpreted as being independent of the others.

\section{RESULTS}

A statistical test of difference in means is performed between EPS_old and EPS_new. Table 1, Panel A presents results of the annual comparison tests between EPS_old and EPS_new. The variable |Diff EPS| represents the absolute value difference of (EPS_new - EPS_old) and the variable Stat indicates if this difference is statistically significantly different from zero. As an example, observe that the difference in EPS in 2002 is 0.34 due to a greater EPS_new. This change in EPS arises from a smaller stock options expense under the new approach (as indicated by the '-' for the variable New_exp). Further, the evidence shows that this difference in EPS is statistically significant at the 0.01 level (as indicated by the '***' for the variable Stat). Results from each independent annual test indicate that the differences in means are statistically different from zero for seven out of ten years. This suggests that using the economic promise approach can significantly alter the reported earnings for companies that have stock options.

To illustrate how the economic promise approach is more closely tied to stock market conditions, we extend the analyses by examining whether stock market pricing trends are in line with the proposed approach. As stated above, results for fiscal year 2002 show that EPS_new is significantly higher than EPS_old. This arises from a smaller stock options expense under the economic promise approach as compared to the current stock option expense. An observation of stock market pricing trends (Table 1, Panel B) reveals that stock prices in general decreased during the 2002 fiscal year (based on the results in variables Chg_Price, S\&P_500, and DJI). This general decrease in stock prices explains the lower stock option expense under the economic promise approach for this fiscal year. An examination of the other years in our sample reveals that this logical pattern, where the proposed stock options expense trends with general stock prices, repeats for all years with statistically significant differences of the variable |Diff_EPS|. The only exception is the fiscal year 2009. For this year, the stock option expense computation was lower under current reporting requirements, yet stock prices in general increased. 


\begin{tabular}{|c|c|c|c|c|c|c|c|c|c|c|}
\hline \multicolumn{11}{|c|}{ Table 1} \\
\hline \multicolumn{11}{|c|}{$\begin{array}{c}\text { Panel A: Difference in means: } \\
\text { Year }\end{array}$} \\
\hline Variable & 2002 & 2003 & 2004 & 2005 & 2006 & 2007 & 2008 & 2009 & 2010 & 2011 \\
\hline EPS_new & 0.35 & 1.12 & 0.15 & 0.23 & 0.57 & 0.43 & 0.02 & -0.20 & 0.54 & 1.30 \\
\hline EPS_old & 0.01 & 1.00 & 0.40 & 0.43 & 0.75 & 0.50 & -0.24 & -0.33 & 0.35 & 0.95 \\
\hline |Diff_EPS| & 0.34 & 0.11 & 0.25 & 0.20 & 0.18 & 0.06 & 0.26 & 0.12 & 0.19 & 0.35 \\
\hline Stat & $* * *$ & & $* * *$ & $* * *$ & $* * *$ & $* * *$ & $* * *$ & $* *$ & & \\
\hline New_exp & - & - & + & + & + & + & - & - & - & - \\
\hline \multicolumn{11}{|c|}{$\begin{array}{c}\text { Panel B: Capital Market Trends } \\
\text { Year }\end{array}$} \\
\hline Variable & 2002 & 2003 & 2004 & 2005 & 2006 & 2007 & 2008 & 2009 & 2010 & 2011 \\
\hline Chg_Price & - & + & + & + & + & - & - & + & + & - \\
\hline S\&P_500 & $-23.8 \%$ & $22.3 \%$ & $9.3 \%$ & $3.8 \%$ & $11.8 \%$ & $3.7 \%$ & $-37.6 \%$ & $19.7 \%$ & $12.8 \%$ & $-1.1 \%$ \\
\hline | ID & $-17.2 \%$ & $21.5 \%$ & $3.6 \%$ & $-0.1 \%$ & $14.9 \%$ & $6.3 \%$ & $-32.7 \%$ & $15.4 \%$ & $11.0 \%$ & $4.7 \%$ \\
\hline \multicolumn{11}{|l|}{ Where: } \\
\hline EPS_new & \multicolumn{10}{|c|}{ Earnings per share valued under the economic promise approach. } \\
\hline EPS_old & \multicolumn{10}{|c|}{ Earnings per share as currently reported. } \\
\hline |Diff_EPS| & \multicolumn{10}{|c|}{ Absolute value difference between eps_new and eps_old. } \\
\hline Stat & \multicolumn{10}{|c|}{ Statistical significance of difference in means where $* * *, * *, *$ refers to a $p$-value of 0.01 and 0.05} \\
\hline New_exp & \multicolumn{10}{|c|}{$\begin{array}{l}\text { Sign of the difference between the economic promise stock option expense and reported stock option } \\
\text { expense. }\end{array}$} \\
\hline Chg_Price & \multicolumn{10}{|c|}{ Sign of the mean change in stock prices for the sample of firms for the fiscal year. } \\
\hline S\&P_500 & \multicolumn{10}{|c|}{ Return on the Standard \& Poors 500 stock index for the fiscal year. } \\
\hline IاJ & \multicolumn{10}{|c|}{ Return on the Dow Jones Industrial stock index for the fiscal year. } \\
\hline
\end{tabular}

\section{SUMMARY, CONCLUSIONS, AND SUGGESTIONS FOR FUTURE RESEARCH}

If the intent of the FASB is to force firms to disclose the true economic cost of options to shareholders, then a model is needed that will account for changing economic conditions and flexible timing of exercise by option holders. Under the economic promise approach, the current calculated amount of the option expense represents the opportunity cost the firm has incurred in a given year. This economic cost represents a dynamic estimate of the cost to shareholders resulting from the negative opportunity cash flows associated with the option and has several advantages over the amount calculated using the BS model. Furthermore, the approach is easy to understand and has low implementation cost. Most importantly, it results in an expense amount that represents market conditions when financial results are reported. Together with the fact that the model reflects the cash flow effects on shareholder wealth associated with options, it should be an attractive alternative to the current option valuation models.

Future research may extend the annual observations to company based observations for each year, where the incremental stock option expense for each company for each year is computed and statistically compared to the amounts currently reported. This process would require assumptions concerning averages for vesting and exercise periods. In addition, the study may be extended to cover industry segments to determine if using the economic promise approach leads to statistically significant differences among companies in different industries.

\section{AUTHOR INFORMATION}

Thomas Smith is an assistant professor of accounting at Florida Atlantic University. He received his Ph.D. in accounting from Florida State University (2010). His research interests include archival financial reporting and 
auditing. He recently published a financial accounting paper in Accounting Horizons and Journal of the American Taxation Association. Prior to entering academia, he worked as an external auditor. E-mail: tsmit158@fau.edu

Adrian Valencia is an assistant professor of accounting at Florida Gulf Coast University. He received his Ph.D. in accounting from Florida State University (2011). His research interests include financial reporting and auditing issues. His research has been published in several journals including Contemporary Accounting Research, Accounting Horizons, and International Journal of Auditing. Prior to entering academia, he worked as a financial accountant and as an external auditor. E-mail: avalencia@fgcu.edu

Ara G. Volkan is the Chair of the Accounting Department at Florida Gulf Coast University. He is an Eminent Scholar and Moorings Park Chair of Managerial Accounting. He received his Ph. D. in accounting from the University of Alabama in 1979 and is a Florida CPA (1989). He taught at Syracuse University (1979-1985) and at University of South Alabama (1986-1989). Next, he chaired the Accounting and Finance Department at University of West Georgia (1989-2003) and was Interim Dean at the Richards College of Business (2003-2004) and at FGCU (2011). He is a member of many academic and professional organizations. E-mail: avolkan@fgcu.edu (Corresponding author)

\section{REFERENCES}

1. Amile, T. T. (2011, July). Measurement of incentive stock option expense: Is the issue settled? The CPA Journal, 28-31.

2. Carter, M. E., Lynch, L. J., \& Tuna, I. (2007, March). The role of accounting in the design of CEO equity compensation. The Accounting Review, 82(2), 327-357.

3. Delves, D. (2002, December). Trend or foe? Analyzing what's behind and beyond the current stock option expensing movement. Strategic Finance, 36-41.

4. Frederickson, J. R., Hodge, F. D., \& Pratt, J. H. (2006, October). The evolution of stock option accounting: Disclosure, voluntary recognition, mandated recognition, and management disavowals. The Accounting Review, 81(5), 1073-1093.

5. Lee, Y.-J. (2008, September). The effects of employee stock options on credit ratings. The Accounting Review, 1273-1314.

6. McEnroe, J. E., Martens, S. C., \& Du, N. (2013, November). Accounting for employee stock options: Examining another option. The CPA Journal, 10-13.

7. O'Shaughnessy, J., \& Rashty, J. (2007, June). Critical accounting estimates for share-based payment arrangements. The CPA Journal, 34-39.

8. Siegel, M. A. (2006, March). Accounting shenanigans on the cash flow statement. The CPA Journal, 38-43. 